\title{
Evaluation of Different Post Lengths' Effect on Fracture Resistance of a Glass Fiber Post System
}

Necdet Adanira, DDS, PhD

Sema Bellib, DDS, PhD

\section{ABSTRACT}

Objectives: The purpose of this in vitro study was to evaluate the influence of different post lengths upon root fracture resistance.

Methods: 78 maxillary central teeth with similar dimensions were mounted in acrylic blocks with artificial silicone periodontal ligaments. Combinations of post lengths of $6 \mathrm{~mm}$ (shorter than $1 / 1$ clinical crown length), $9 \mathrm{~mm}$ (1/1 clinical crown length), and $12 \mathrm{~mm}$ (longer than $1 / 1$ clinical crown length) made up 6 different groups consisting of 13 teeth each. The glass fiber posts (Snowpost) were cemented with Super-Bond C\&B and Panavia F luting cement. Composite-resin cores were made with Clearfil PhotoCore. The specimens were tested in a universal test machine. The testing machine applied controlled loads to the core, $2 \mathrm{~mm}$ from its incisal edge, on the palatal side at an angle 135 degrees to the long axis of the root. The testing machine was set at a crosshead speed of $5 \mathrm{~mm}$ per minute. All samples were loaded until failure.

Results: There was no statistically significant difference between cements $(P>$.05). Posts shorter than clinical crown length, demonstrated root fracture under significantly lower loading forces $(\mathrm{P}<.05)$.

Conclusion: Usage of posts shorter than clinical crowns should be avoided to eliminate clinical failure. (Eur J Dent 2008;2:23-28)

Key words: Post length; Fiber post; Fracture resistance; Resin cement; Root canal treatment.

\section{INTRODUCTION}

Restoration of endodontically treated teeth is still a controversial subject on present days. It is well known that those teeth are generally weaker due to decay, previous restorative procedures

assistant Professor, Department of Endodontics, Faculty of Dentistry, S. Demirel University, Isparta, Turkey.

b Professor, Department of Endodontics, Faculty of Dentistry, Selcuk University, Konya, Turkey.

- Corresponding Author: Dr. Necdet ADANIR S. Demirel Universitesi, Dishekimligi Fakultesi, Endodonti AD., Dogu Kampusu, 32060 Isparta / TURKIYE Tel: + 902462113287 Fax: + 902462370607 E-mail: necdetdadanir.org and endodontic access preparation ${ }^{1-3}$ or loss of moisture supplied by a vital pulp. ${ }^{4}$ The restoration of such teeth is commonly accomplished using post and core, to prevent further destruction and create retention and resistance, before the placement of a crown or a fixed partial denture. ${ }^{5-7}$

There are various post and core systems. The most widely used systems can be classified into two basic types; metal posts and cores that are custom cast as a single piece, and two element designs including a prefabricated post to which an amalgam or composite core is subsequently adapted. Cast metal post and core application is relatively more time consuming and demands 
extra clinic and laboratory time. ${ }^{8}$ In addition, the use of metal alloys posts and cores under the allceramic crowns exhibits aesthetic problem. On the contrary, prefabricated posts allow fast, cheap and easy techniques. 5,9

Previously, prefabricated posts made of stainless steel, titanium, or precious alloy were used. Recently, with respect to prefabricated post materials, various types of fiber posts have been introduced to the dental community, including zircon posts, woven polyethylene fiber posts, quartz fiber posts and glass fiber posts. ${ }^{10-12}$ The use of such materials offer a number of advantages, including biocompatibility, esthetic properties, dentin-like rigidity, resistance to corrosion and fatigue, mechanical properties that closely match those of tooth ${ }^{13,14}$ and option of easy removal of post from the root canals. ${ }^{15}$ Among of these, the most important feature of glass fiber post is chemical adhesion with bonding cement and composite resin cores. ${ }^{16,17}$ This advantage provides more conservative post hole preparation.

A wide range of recommendations have been made regarding post length for conventional posts, which includes the following: (a) the post length should equal the clinical crown; (b) the post should be longer than the clinical crown; (c) the post should be half the root length; (d) the post should be two-thirds the root length; (e) the post should be four-fifths the root length and ( $f$ ) the post should be as long as possible without disturbing the apical seal. ${ }^{18}$

Whereas recent reports suggest that the rigidity of the post should be equal or close to that of the tooth to distribute the occlusal forces evenly along the length of the root, ${ }^{19,20}$ post length within the root canal is still controversial. Therefore, the purpose of this in vitro study was to evaluate the influence of different post lengths upon root fracture resistance of a glass fiber post system. During fracture resistance tests, it was also aimed to evaluate adhesive properties of two resin cement.

\section{MATERIALS AND METHODS}

Seventy-eight maxillary central incisors freshly extracted for periodontal reasons, with straight root canals, anatomically similar root segments, and fully developed apices, used for this study. Soft tissue and calculus were mechanically removed from these teeth. Mesiodistal and buccopalatal dimensions and root lengths of all selected teeth were measured using digital calipers (Best Co., Japan).

The crowns were removed with a slow-speed diamond saw (Isomet, Buehler Ltd., Evanston, IL) at the enamel-cement junction. After pulp tissue was removed, the canal lengths were visually established by placing a \#15 file into each root canal until the tip were visible at the apical foramen. The working lengths were established 1 $\mathrm{mm}$ short of the apex. All teeth were instrumented at working length using the standard step-back method with $5.25 \%$ sodium hypochlorite irrigation. The prepared teeth were dried with paper-points (Diadent Group International Inc., Chongju, Korea) and filled with laterally compacted gutta-percha (Diadent Group International Inc., Chongju, Korea) and epoxy-resin based AH Plus (DeTrey Dentsply $A G$, Zürich, Switzerland) root canal sealer. The teeth were randomly divided into six equal groups of 13 .

Group I: Post holes were prepared shorter than $1 / 1$ clinical crown length $(6 \mathrm{~mm})$ using a drill recommended by manufacturer (Carbotech, Ganges, France). After irrigation and drying of the canals, equal amounts of ED Primer liquids $A$ and B (Kuraray Co Ltd, Osaka, Japan) were mixed together on the mixing dish. The walls of root canals were treated with a self-etching ED primer for 60 seconds. Excess liquid was eliminated with a paper point before completely drying the primer with a gentle airflow. Equal amounts of Panavia F paste A and B (Kuraray Co Ltd, Osaka, Japan) was mixed for 20 seconds and placed in the post spaces using a lentulo spiral instrument (Mani Inc., Tochigi-Ken, Japan). The glass fiber posts were (Carbotech, Ganges, France) covered with cement and slowly inserted into the root canal by finger pressure. The excess cement was carefully removed. The dual cured cement was polymerized for 40 seconds with the same light-polymerizing unit (Curing Light XL 3000; 3M, St Paul, MN, USA). Oxyguard II gel (Kuraray, Osaka, Japan) was applied to the bonding margins of Panavia $F$ cement for 3 minutes.

Group II: 1/1 clinical crown length were used for post lengths $(9 \mathrm{~mm})$. The other procedures were the same as in Group I.

Group III: In this group, post holes were 
prepared longer than $1 / 1$ clinical crown length 112 $\mathrm{mm}$ ) using drill. The samples were prepared as in Group I.

Group IV: Post holes were prepared the same as Group I but Super-Bond C\&B (Sun Medical Co. Ltd, Shiga, Japan) was used for luting procedures. Canal walls were treated with green activator for 10 second, rinsed with water thoroughly, and dried with paper points. Super-Bond C\&B resin was prepared by mixing four drops of monomer with one drop of catalyst in a cool ceramic well and introduced with a brush inside the canal to wet the dentin walls. The same procedure was done on the glass fiber post. Then two scoops Super-Bond C\&B radio-opaque powder were added to a fresh mix of base and catalyst to prepare the luting cement, which was inserted inside the canal using a lentulo spiral (Mani Inc., Tochigi-Ken, Japan). Finally the post was inserted into the post space and held in place for $10 \mathrm{~min}$.

Group V: Post holes were prepared $1 / 1$ clinical crown length $(9 \mathrm{~mm})$ using drill and Super-Bond C\&B was used for luting procedures as in Group IV.

Group VI: Post holes were prepared longer than $1 / 1$ clinical crown length $(12 \mathrm{~mm})$ using drill. The samples were prepared as in Group IV using Super-Bond C\&B.

The coronal core portion was made with a lightcured hybrid core build-up composite (Clearfil PhotoCore, Kuraray Co Ltd, Osaka, Japan) for all samples. The roots were immersed into melted wax to a depth $2 \mathrm{~mm}$ below the facial CEJ to produce a 0.2 to $0.3 \mathrm{~mm}$ layer described by Sirimai et al. ${ }^{11}$ Teeth were mounted in acrylic resin blocks. Each tooth was removed from the resin block when the first signs of polymerization were observed. The wax spacer was removed from the root surface and alveolus of the acrylic resin block. Injection type polyvinyl siloxane impression material (ColtenéWhaledent, Altstätten, Switzerland) was delivered with the dispenser gun through the mixing tip into the acrylic resin alveolus. The tooth was then reinserted into the test block, and the impression material was allowed to set. Excess silicone material was removed with a scalpel blade to provide a flat surface $2 \mathrm{~mm}$ below the facial CEJ of each tooth. In this manner, approximately equal to the average thickness of the periodontal ligament was achieved. The thin layer of silicone material was simulated periodontal ligament. After previously mentioned procedures, specimens were stored in $100 \%$ humidity at $37^{\circ} \mathrm{C}$ for 24 hours.

A modified device, described Cobankara et al, ${ }^{21}$ was made for loading of the tooth at an angle of 135 degrees to its long axis (Figure 1). Teeth were placed in to a retention device, mounted into a Universal Testing Machine (Testometric Micro 500, England), and a controlled loading force were applied to the teeth at a crosshead speed of $5 \mathrm{~mm} /$ min. All samples were loaded until failure. The loading force $(\mathrm{N})$ required to cause failure were recorded, and the type of fracture were recorded as the core debonded, the post fracture, or the tooth fractured.

\section{Statistical analysis}

Descriptive statistics, including the mean, standard deviation, standard error, minimum and maximum values were calculated for each of the groups tested. A two-way analysis of variance (ANOVA) was used to analyze the data for significant differences. For analyze differences within groups, the Friedman one-way ANOVA, followed by Wilcoxon signed-rank test was carried out. The chi-square test was used to determine significant differences in the type of failure. Significance for all statistical tests was predetermined at $P<.05$. All statistics were performed with SPSS version 10.0.8 (SPSS Inc., Chicago, IL, USA).

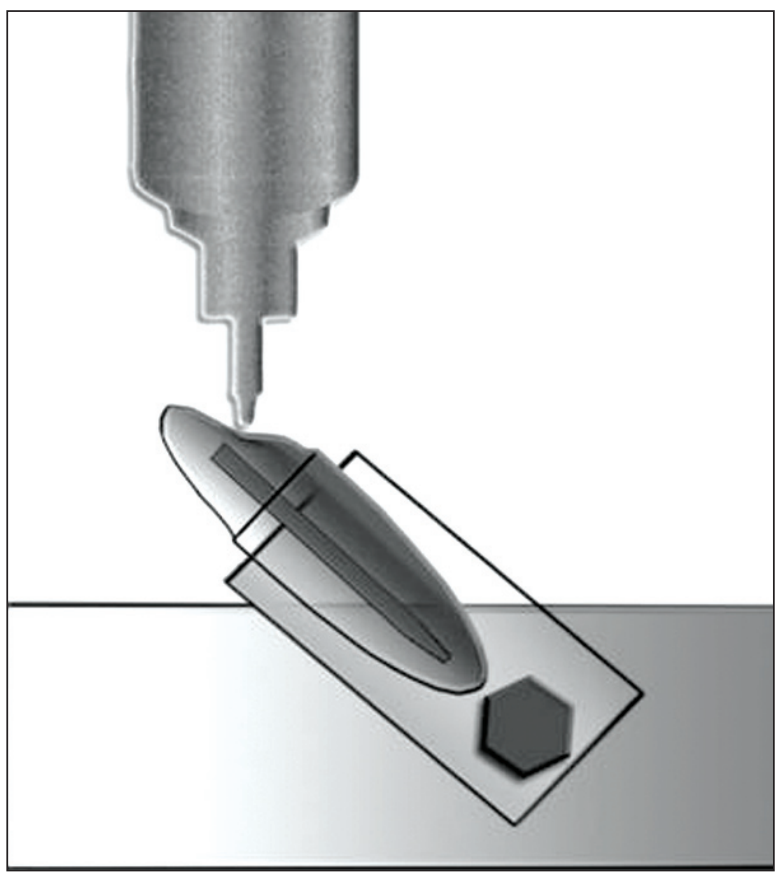

Figure 1. Diagram of restored tooth embedded in acrylic resin. 


\section{RESULTS}

The results from both the experimental groups are shown in Table 1. Statistical analysis revealed that groups I and IV, post length shorter than clinical crown length, were significantly less fracture resistant than other tested groups ( $P<.05)$. There were no statistically significant differences in luting cement ( $P>$.05). No significant differences in fracture resistance were noted groups II, III, V, VI (P>.05).

Failure mode was summarized in Table 2. There were two post fractures in groups IV and VI which luted with Super-Bond C\&B. Groups I and IV, which had post lengths shorter than clinical crown length, showed more root fracture than other examined groups $(\mathrm{P}<.05)$.

\section{DISCUSSION}

This study's primary aim was to evaluate different post lengths' effect on fracture resistance of a glass fiber post system. The fracture resistances of two different resin cements under functional forces were also evaluated.

Inthis invitrostudy, teethwere carefullyselected for standardized size. This is an important variation in the resistance to fracture of the specimens. ${ }^{11}$ The mean size of the roots was $16.43 \pm 0.22 \mathrm{~mm}$ in length, $6.45 \pm 0.12 \mathrm{~mm}$ in mesiodistal, and $7.25 \pm 0.25 \mathrm{~mm}$ in buccopalatal width. There was no significant difference between mean root lengths and mesiodistal and buccopalatal diameters of roots. This data revealed that the samples used in this study were acceptable as standard.

The loading was applied to the experimental teeth at an angle of $135^{\circ}$ to the long axis to teeth. This angle reflects the positions, contacts

Table 1. Mean, standard deviation, minimum and maximum fracture resistance $(\mathrm{N})$ for each group.

\begin{tabular}{l|c|c|c|c}
\hline Groups & $\mathrm{n}$ & Mean $\pm \mathrm{SD}(\mathrm{N})$ & Minimum & Maximum \\
\hline I & 13 & $642.5 \pm 49.6^{\mathrm{a}}$ & 510.3 & 706.4 \\
\hline II & 13 & $1037.7 \pm 72.9^{\mathrm{b}}$ & 949.8 & 1155.6 \\
\hline $\mathrm{III}$ & 13 & $1055.3 \pm 74.4^{\mathrm{b}}$ & 954.5 & 1179.8 \\
IV & 13 & $628.7 \pm 23.2^{\mathrm{a}}$ & 576.7 & 658.9 \\
V & 13 & $998.3 \pm 65.9^{\mathrm{b}}$ & 901.1 & 1130.5 \\
\hline VI & 13 & $1032.8 \pm 69.1^{\mathrm{b}}$ & 903.1 & 1150.6 \\
\hline
\end{tabular}

Mean values with the same superscript letters are not statistically different at $\mathrm{P}<.05$ level. and loading characteristics of upper anterior teeth in Class I occlusion. ${ }^{22}$ This mode of loading was adopted from the methodology utilized by those authors who also evaluated the fracture resistances of maxillary incisor teeth..$^{23,24}$

It is believed that the use of a rigid material to embedded extracted teeth may lead to distorted load values and possibly affect the mode of failure of the specimens. ${ }^{25}$ In this study, roots were not embedded directly into the resin blocks. The thin layers of polyvinyl siloxane simulated periodontal ligaments. Because we did not embed the roots directly into the acrylic resin blocks, external reinforcement of the root structure by the rigid acrylic resin was avoided. ${ }^{11}$

In the present study, clinical crown length was accepted as approx. $9 \mathrm{~mm}$ long. ${ }^{26}$ Therefore, in groups III and VI, post lengths longer than clinical crown lengths were $12 \mathrm{~mm}$. In groups I and IV post lengths were $6 \mathrm{~mm}$ shorter than clinical crown. In groups II and V, the post lengths were 9 $\mathrm{mm}$. Variations were observed in between-group comparisons of the present study. Statistical analysis revealed that groups I and IV (post lengths shorter than clinical crown lengths) were significantly less fracture resistant than other tested groups regardless luting cement $(P<.05)$. In mathematical model study, Adanir et al ${ }^{27}$ reported that when the post length was shorter than clinical crown, stress accumulation was increased on cervical buccal area. This result agrees with the present study. Statistical analysis revealed that more root fracture was observed in short post groups compared with other tested groups (Figure 2).

There was no statistically significant difference

Table 2. Failure mode for each group.

\begin{tabular}{lccc}
\cline { 2 - 4 } Groups & \multicolumn{3}{c}{ Failure Modes } \\
\hline Fracture & Fracture & $\begin{array}{c}\text { Root } \\
\text { Fracture }\end{array}$ \\
\hline I & 4 & - & 9 \\
II & 12 & - & 1 \\
III & 11 & - & 2 \\
IV & 2 & 1 & 10 \\
V & 11 & - & 2 \\
VI & 11 & 1 & 1 \\
\hline
\end{tabular}


between equal and long post groups ( $P>$.05). Many authors have offered guidelines for determining the desired post length. It's well known that the longer the post in the canal, the more retentive it is. ${ }^{28,29}$ However, increased post length also increases risk of fracture and perforation of the remaining root. Previous studies revealed that as dowel length increases beyond two thirds of the root, the stresses in the apical region increase and post length extension may damage the root apical sealing. ${ }^{27,30}$ In this respect, the apical 3 to $6 \mathrm{~mm}$ of gutta-percha must be preserved to maintain the apical seal. ${ }^{31,32}$ Our study demonstrated that posts with $9 \mathrm{~mm}$ length were similar to posts with $12 \mathrm{~mm}$ length. Nissan et $a^{28}$ also reported no significant difference in retention of posts with $8 \mathrm{~mm}$ and 10 $\mathrm{mm}$ lengths. Therefore, we assume that in clinical conditions of anatomical variations such as short root, a post of clinical crown length $(9 \mathrm{~mm})$ can be a viable alternative.

Panavia $F$ was provided more resistance to fracture when compared to Super-Bond C\&B but no statistically significant differences were found among the resin cements ( $P>$.05).

None of the teeth were restored with an artificial crown and ferrule in this study. Assif et al ${ }^{19}$ reported that the complete crown with a 2 $\mathrm{mm}$ ferrule on sound tooth structure changed the distribution of forces to the root and the post-core system. If complete crowns with $2 \mathrm{~mm}$ ferrules were made, the results of this study might have been different.

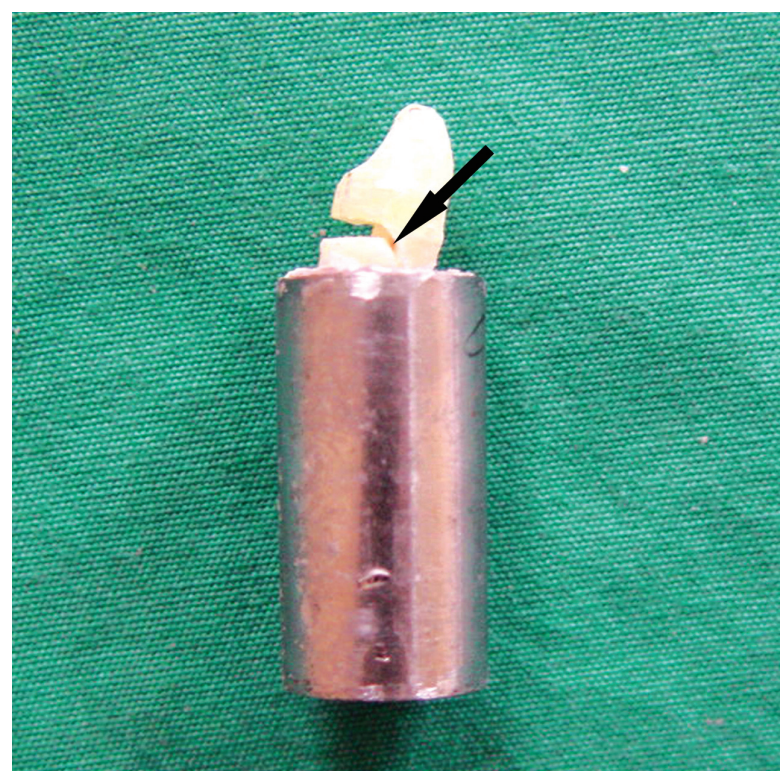

Figure 2. Root has fractured obliquely at proximal surface into alveolus.

\section{CONCLUSIONS}

1. The post length should not be shorter than clinical crown length when glass fiber posts are used.

2. Post lengths equal to clinical crown length yielded adequate fracture resistance. Therefore more post preparation is not needed.

\section{REFERENCES}

1. Reeh ES, Messer $\mathrm{HH}$, Douglas WH. Reduction in tooth stiffness as a result of endodontic and restorative procedures. J Endod 1989;15:512-516.

2. Sorensen JA, Engelman MJ. Ferrule design and fracture resistance of endodontically treated teeth. $J$ Prosthet Dent 1990;63:529-536.

3. Sedgley $\mathrm{CM}, \mathrm{Messer} \mathrm{HH}$. Are endodontically treated teeth more brittle? J Endodon 1992;18:332-335.

4. Carter JM, Sorensen SE, Johnson RR, Teitelbaum RL, Levine MS. Punch shear testing of extracted vital and endodontically treated teeth. J Biomech 1983;16:841-848.

5. Hudis SI, Goldstein GR. Restoration of endodontically treated teeth: a review of the literature. J Prosthet Dent 1986;55:33-38.

6. Plasmans PJ, Welle PR, Vrijhoef MM. In vitro resistance of composite resin dowel and cores. J Endod 1988;14:300304.

7. Assif D, Gorfil C. Biomechanical considerations in restoring endodontically treated teeth. J Prosthet Dent 1994;71:565567.

8. DeSort KD. The prosthodontic use of endodontically treated teeth: theory and biomechanics of post preparation. $J$ Prosthet Dent 1983;49:203-206.

9. Kern SB, von Fraunhofer JA, Mueninghoff LA. An in vitro comparison of two dowel and core techniques for endodontically treated molars. J Prosthet Dent 1984;51:509514.

10. Goldberg AJ, Burstone CJ. The use of continuous fiber reinforcement in dentistry. Dent Mater 1992;8:197-202.

11. Sirimai S, Riis DN, Morgano SM. An in vitro study of the fracture resistance and the incidence ofvertical root fracture of pulpless teeth restored with six post-andcoresystems. J Prosthet Dent 1999;81:262-269.

12. Eskitascioḡlu G, Belli S, Kalkan M. Evaluation of two post core systems using two different methods (fracture strength test and a finite elemental stress analysis). $J$ Endod 2002;28:629-633.

13. Sorensen JA, Engelman MJ. Effect of post adaptation on fracture resistance of endodontically treated teeth. $J$ Prosthet Dent 1990;64:419-424.

14. King PA, Setchell DJ. An in vitro evaluation of a prototype 
CFRC prefabricated post developed for the restoration of pulpless teeth. J Oral Rehabil 1990;17:599-609. 15. Purton DG, Love RM. Rigidity and retention of carbon fiber versus stainless steel root canal posts. Int Endod J 1996;29:262265.

16. Ferrari M, Vichi A, Grandini S. Efficacy of different adhesive techniques on bonding to root canal walls: an SEM investigation. Dent Mater 2001;17:422-429.

17. Kalkan M, Usumez A, Ozturk AN, Belli S, Eskitascioglu G. Bond strength between root dentin and three glass-fiber post systems. J Prosthet Dent 2006;96:41-46.

18. Goodacre CJ, Kan JYK. Restoration of endodontically treated teeth. In: Ingle JI and Bakland LK ed. Endodontics. London: BC Decker Inc., 2002:922.

19. Assif D, Bitenski A, Pilo R, Oren E. Effect of post design on resistance to fracture of endodontically treated teeth with complete crowns. J Prosthet Dent 1993;69:36-40.

20. Isidor F, Odman P, Brøndum K. Intermittent loading of teeth restored using prefabricated carbon fiber posts. Int J Prosthodont 1996;9:131-136.

21. Cobankara FK, Ungor M, Belli S. The effect of two different root canal sealers and smear layer on resistance to root fracture. J Endod 2002;28:606-609.

22. Lauer HC, Ottl P, Weigl P. Mechanical load-bearing capacity of various post-and-core systems. Dtsch Zahnarztl Z 1994;49:985-985.

23. Ottl P, Hahn L, Lauer CH, Fay M. Fracture characteristics of carbon fibre, ceramic and non-palladium endodontic post systems at monotonously increasing loads. $J$ Oral Rehabil 2002;29:175-183.

24. Hu YH, Pang LC, Hsu CC, Lau YH. Fracture resistance of endodontically treated anterior teeth restored with four post-and-core systems. Quintessence Int 2003; 34:349-353.

25. Newman MP, Yaman P, Dennison J, Rafter M, Billy E. Fracture resistance of endodontically treated teeth restored with composite posts. J Prosthet Dent 2003; 89:360367.

26. Alaçam T. Endodonti. Ankara: Barıs yayınları, 2000.

27. Adanir N, Belli S, Eraslan O, Eskitascioglu G. Bir cam fiber post sistemiyle restore edilmiş üst birinci kesici diș modelinde post uzunluḡunun fonksiyonel kuvvetler altında oluşan stress daḡılımına etkisi. Türk Dişhekimliği Dergisi 2005;59:8-12.

28. Nissan J, Dmitry $Y$, Assif D. The use of reinforced composite resin cement as compensation for reduced post length. $J$ Prosthet Dent 2001;86:304-308.

29. Braga NM, Paulino SM, Alfredo E, Sousa-Neto MD, Vansan LP. Removal resistance of glass-fiber and metallic cast posts with different lengths. J Oral Sci 2006;48:15-20.

30. Yang HS, Lang LA, Molina A, Felton DA. The effects of dowel design and load dirction on dowel-and-core restorations. $J$ Prosthet Dent 2001;85:558-67

31. Kvist T, Rydin E, Reit C. The relative frequency of periapical lesions in teeth with root canal-retained posts. $J$ Endod 1989;15:578-580.

32. Goodacre CJ, Kan JYK. Restoration of endodontically treated teeth. In: Ingle JI and Bakland LK ed. Endodontics. London: BC Decker Inc., 2002:928. 